\title{
Prenatal contraceptive counseling and method provision after childbirth
}

\author{
This article was published in the following Dove Press journal: \\ Open Access Journal of Contraception \\ 13 May 2015 \\ Number of times this article has been viewed
}

\author{
Anita L Nelson \\ Los Angeles Biomedical Research \\ Institute, Harbor-UCLA Medical \\ Center, Torrance, CA, USA
}

Correspondence: Anita L Nelson 1457 3rd St, Manhattan Beach, CA 90266, USA

Tel + I 3109377226

Fax + I 310937 |4I6

Email anitalnelson@earthlink.net
Abstract: Postpartum contraception is undergoing major changes, not only in timing, but also in content. Failure to provide immediate postpartum contraception contributes to the problems of unintended pregnancies and rapid repeat pregnancy because often the highest-risk women do not return for postpartum care. If they do attend that visit, they have often lost the insurance coverage that would enable them to use the most effective forms of birth control. Most of the issues surrounding early initiation of progestin-only methods and breastfeeding have been favorably resolved. In some cases, insurance coverage for delivery has been expanded to cover the costs of providing intrauterine devices and implants before the woman is discharged home. All of these new opportunities shift the burden of counseling about postpartum contraception onto the shoulders of the prenatal care provider. This article provides information about the advantages and disadvantages of providing immediate postpartum contraception with each of the eligible methods so clinicians can provide the needed counseling both during pregnancy and during hospitalization for delivery. It also provides guidance for initiation of bridging contraception, if needed, to initiate a method for a woman later in the postpartum period.

Keywords: postpartum contraception, counseling, breastfeeding, implants, IUDs, hormonal methods

\section{Introduction}

The traditional paradigm of starting contraception at a woman's 6 week postpartum visit has been revolutionized, as the emphasis is shifting to providing women with the most effective methods as soon as possible postpartum. ${ }^{1}$ The interest in postpartum contraception has been ignited by several forces. The optimal interpregnancy interval has been better defined. A number of studies have clearly established the safety and efficacy of providing top-tier contraceptive methods to women immediately after delivery, whereas they have shown that postpartum "bridging" methods and plans for delayed initiation of top-tier reversible methods or permanent contraception result in relatively high repeat pregnancy rates. Some state Medicaid programs will now reimburse for immediate postpartum placement of intrauterine devices (IUDs) and implants outside the global fee, covering both the costs of the devices and the placement procedures, and momentum has been building to expand that coverage into other states and other insurance carriers. ${ }^{2,3}$ Evidence-based clinical recommendations for selection of appropriate methods for rapid postpartum contraception have been provided by the Centers for Disease Control and Prevention (CDC). ${ }^{4}$ Guidance has also been provided by the CDC about procedures needed to assess a woman before method initiation and how to follow her afterward. ${ }^{5}$ Professional associations, such 
as America College of Obstetricians and Gynecologists and the American Academy of Pediatrics, recommend that a primary focus of routine prenatal and postpartum care should include a discussion of contraceptive options and prompt initiation of a method postpartum. ${ }^{6,7}$ Noncontraceptive health benefits of contraceptive methods for breastfeeding women have been identified. ${ }^{8}$ This strong trend toward initiation of contraception prior to postpartum discharge home highlights the need for antepartum patient counseling about postpartum contraception. To provide a basis for counseling women about these postpartum methods, this review will summarize the latest developments in each of these areas.

\section{Optimal interpregnancy interval}

A large study based on birth certificate data from 1989 to 1996 concluded that the optimal interpregnancy interval is 18-23 months. $^{9}$ In that study, if the interval was less than 6 months, the risk for low birthweight was increased by $40 \%$, preterm birth risk increased by $40 \%$, while small for gestational age risk was increased by $30 \% .{ }^{10}$ The risk for preterm delivery is greatest for earlier gestational age $(<34$ weeks; odds ratio [OR], 3.9), rather than later preterm, deliveries (34-37 weeks). ${ }^{11}$ Others have confirmed that intervals of less than 6 months and 6-12 months increase the risk for extreme preterm birth and recurrent preterm birth. ${ }^{12}$ Rapid repeat births to adolescents increase the risk of preterm and low-birth weight babies to levels higher even than those observed with their first pregnancies ${ }^{13}$ and in a dose-dependent fashion. ${ }^{14}$ Speroff has reminded clinicians that an interpregnancy interval of less than 2 years impacts not only the second child (higher risks for low birth weight, preterm delivery, and infant death) but also the first child (who is placed at higher risk for malnutrition and infection). ${ }^{1}$

The reality is that despite these risks, one third of all repeat pregnancies in the United States are conceived within 18 months of a prior birth. ${ }^{15}$ Half of all unintended pregnancies to parous women occur within 2 years of a previous birth. Minority and low-income women are more likely to have short birth intervals as a result of unintended pregnancies compared to middle class or Caucasian women. ${ }^{15}$ One in five teen births in the United States is a repeat birth, often within a short interval of the first delivery. ${ }^{12}$

\section{Return to fertility}

An important question to consider when counseling women about the need for postpartum contraception is, how soon do they need to start using it? Overall, $25 \%$ of women ovulate between 25 and 39 days postpartum, long before the traditional 6 week postpartum visit. ${ }^{16}$ It has been estimated that more than $50 \%$ of first menses after delivery are preceded by ovulation and that $50 \%$ of those ovulations have active luteal phases. Younger women have a more rapid return to fertility postpartum than older women. ${ }^{17}$ While exclusive breastfeeding can suppress ovulation, up to half of women who partially breastfeed ovulate before 6 weeks postpartum. ${ }^{14}$ One large prospective study showed that before breastfeeding women returned for their routine 6 week postpartum visits, nearly one quarter of them stopped breastfeeding altogether, and approximately another $50 \%$ had converted to partial breastfeeding. ${ }^{18}$

\section{Need for contraception postpartum}

Postpartum intentions often radically change with time. After delivery, most young women intend to avoid pregnancy; however, many become ambivalent within months. ${ }^{19}$ Anecdotally, most clinicians can recall the sincerity and total conviction with which many young mothers declare they do not need contraception because they plan to never have sex again. At that moment, they appear to be firmly committed to abstinence. However, studies have reported that one in five women of all ages resumed sexual activity before 4 weeks postpartum. ${ }^{20}$ In the United States, teens have a $35 \%$ rate of repeat pregnancy within 2 years. ${ }^{19}$ On the other hand, adolescent women tend to be better at using contraceptives after a teenaged birth than they were before becoming pregnant (91\% use a method vs 50\% prepregnancy). ${ }^{12}$ Among adolescent women, lack of contraceptive use is more likely with early resumption of coitus. ${ }^{19}$ Another predictor of lack of contraceptive use is a prior unintended teenaged pregnancy, which could be a proxy for the young woman's fundamental sense of lack of control over events in her life or her beliefs about the inappropriateness of planning pregnancy.

Paradoxically, young women who deliver prematurely are also at higher risk for failure to use contraception. ${ }^{19}$ In the Philadelphia Collaborative Preterm Prevention Project, 566 sexually active women who delivered at or before 35 weeks' gestational age were followed for 6 months. Over $90 \%$ of those women said they had no desire for another pregnancy within 12 months, but over half (54.6\%) used low or moderately effective contraceptive methods, including $16.3 \%$ who relied on coitus interruptus. ${ }^{21}$

This same pattern has been reported in many other settings. In one study, $12 \%$ of postpartum women surveyed 3-4 months after delivery reported not using any method, and only $62 \%$ reported using a first- or second-tier method. ${ }^{22}$ 
Even when women desire to use an effective method, they may not have realistic access to it postpartum. ${ }^{23} \mathrm{~A}$ study from New Mexico found that only $60 \%$ of postpartum women who requested an IUD actually obtained one while they were followed-up postpartum within the system; one of the most common reasons for not getting an IUD was an early repeat pregnancy. ${ }^{24}$

\section{Postpartum follow-up care}

The tradition of initiating contraception at the 6 week postpartum visit developed at a time when women typically used diaphragms for contraception. Diaphragms could not be fitted until the cervix normalized postpartum (generally around 6 weeks). However, today we recognize that 6 weeks is far too late to meet the real-world needs of the postpartum patient. ${ }^{14}$

According to self-reported answers obtained 4 months postpartum for the CDC Pregnancy Risk Assessment Monitoring System (PRAMS) 2004 data from 11 states and New York City, $89 \%$ of US women who deliver attend a postpartum care visit. However, only $71 \%$ of women who had late prenatal care or who had $\leq 8$ of education kept their postpartum visits. New mothers have limited time to dedicate to their own personal health; they are often sleep-deprived, overwhelmed, and vulnerable to postpartum depression. Women who have had poor outcomes (preterm, low birthweight, and stillborn or infant death) have lower utilization of postpartum care..$^{25}$ Sociodemographic factors, especially coverage for postpartum care, can override the best of intentions. Recent immigrants can be challenged by lack of coverage and communication problems. Cultural norms, such as the need for partner involvement/agreement in method choice, can delay initiation of birth control if contraceptive discussions are postponed until the postpartum period. In a study of over 4,000 women in Los Angeles County (where postpartum contraception is free to indigent uninsured residents) the top reasons given by 327 women who did not receive any of those services were "felt tired" $(42 \%)$, "too busy with baby" (31\%), "other things going on" (30\%), and "no need for it" $(26 \%) .{ }^{26}$ The authors suggested that if the importance of postpartum visits were emphasized during prenatal care, women might follow up in greater numbers. Another study looked at databases for birth records and those for publically funded family planning to assess postpartum utilization of contraception. They found that only $41 \%$ of the 117,644 eligible postpartum women had a contraceptive claim made within 90 days of delivery, and 4 in 10 women became pregnant within 18 months. Those women who did not receive contraception in the first 90 days were more likely to have short-interval repeat pregnancies..$^{27}$ Other women can face even longer delays in accessing long-acting reversible contraception methods because extra and unnecessary testing is ordered or because insurance coverage needs to be confirmed and supplies need to be obtained. ${ }^{28}$ The CDC goal of same-day service is not yet available throughout the United States. Making sure women have ongoing methods to use should they not attend their postpartum visit or should their insurance coverage lapse before they receive their devices would help reduce unintended pregnancies. ${ }^{1}$ To make this possible, antenatal counseling about contraceptive choices becomes critical so the woman can take action before she leaves the hospital, particularly if she decides on one of the most effective methods.

\section{Prenatal counseling}

Prenatal counseling about contraception is part of a large complex of topics about which pregnant women need to be educated. A recent telephone survey of 274 women who had delivered within the prior 2 weeks asked the women's perceptions of the antepartum preparation they had for a wide array of postpartum changes. The only postpartum change that more than half of the women said they had been prepared for was vaginal bleeding. Although more than $60 \%$ of women reported having problems with breastfeeding, mood swings, and their own appearances, only $18 \%-45 \%$ said they had been prepared by antepartum counseling for those problems. ${ }^{29}$

Antepartum contraception counseling has been shown to increase postpartum use of contraception by adult women ${ }^{30,31}$ and teenagers. ${ }^{32}$ Women whose pregnancy was unintended were significantly more likely to use contraception postpartum if they received prenatal counseling $(83.6 \%)$ than if they received no counseling $(16.4 \% ; P<0.01) .{ }^{33}$ In a recent analysis of the Pregnancy Risk Assessment Monitoring System 2004-2005, women who received either prenatal or postpartum contraceptive counseling were more likely to use a more effective method postpartum ( $49 \%$ vs $32 \%$; adjusted OR, 2.1; 95\% confidence interval [CI], 1.65-2.67). Women who received counseling at both times had even higher acceptance rates (56\% vs 32\%; adjusted OR, 2.33; 95\% CI, 1.87-2.89). Women with Medicaid and those with no health insurance before pregnancy benefited the most from counseling. ${ }^{34} \mathrm{~A}$ Cochrane Review of eight randomized controlled studies found that postpartum counseling can increase postpartum contraceptive use. ${ }^{35}$ However, just assuming that postpartum women will return to a method she had previously 
used is not adequate. With counseling, $46 \%$ of postpartum women changed the method they had previously used to one that was easier to use, afforded long-term protection, and did not require monthly pharmacy trips. ${ }^{36}$

Despite its demonstrated efficacy, prenatal counseling about contraception is not always provided. A review of 528 deliveries in Los Angeles County in 2007 found that only $75.4 \%$ of patients had documented an antenatal contraceptive plan. Non-Hispanic white women were $50 \%$ more likely to have had contraceptive counseling documented than women in other racial or ethnic groups ${ }^{37}$ Contraceptive plans were more likely to be found in a woman's medical record if she had attended more visits ( $>10$; adjusted OR, 6.2; 95\% CI, 2.9-13.2) and if she had been seen by a nurse practitioner (adjusted OR, 6.2; 95\% CI, 2.9-7.0). ${ }^{37}$

Even during an uncomplicated pregnancy, women have to assimilate a tremendous amount of new information. When young minority women were asked what they thought would be the best way to learn about their contraceptive options during pregnancy, they recommended frequent, short episodes of contraception counseling throughout pregnancy in order to explain contraception "step by step." They agreed that such counseling is best done during pregnancy, "when you have time to decide." Following delivery, they requested a review of options, reassuring and reinforcing decisions. If there was still a remaining need at the postpartum visit, they advised that all items included in the postpartum counseling be repeated and that clinicians not assume that the women would retain any of the earlier information. Importantly, they urged that multiple ways of teaching be used. ${ }^{38}$

This last suggestion was underscored in a recent study that examined the potential contribution that adjunctive social media made to effective contraceptive counseling. When standard contraceptive education with pamphlets given to nonpregnant women was compared to standard contraceptive education with Facebook, the Facebook group had higher knowledge scores and higher satisfaction scores, and preference for long-acting reversible contraception methods was greater. ${ }^{39}$ This finding should not be surprising, given the great reliance many people place on information they find online. In contrast, use of a postpartum educational script similar to that used in the CHOICE Study focusing on IUD and implant use did not increase uptake of those methods at the 6 week postpartum visit. ${ }^{40}$ Focused contraceptive counseling and case management before hospital discharge did increase later postpartum use of highly effective methods among women at high risk for preterm birth. ${ }^{41}$

\section{Postpartum contraception: general issues in method selection}

Given that there is a distinct need for prompt hospital-based initiation of contraception, several general issues remain, including impacts on breastfeeding, technical challenges, and financial feasibility.

\section{Impacts on breastfeeding}

Breastfeeding provides demonstrable health benefits to the infant and the mother ${ }^{42}$ and enhances the very important bond between them. Exclusive breastfeeding when accompanied by amenorrhea can provide rather impressive contraceptive protection ( $2 \%$ pregnancy rate) for the first 6 months (lactational amenorrhea). Clearly, every woman seeking to breastfeed her baby needs support and education not only about the technical aspects of getting the infant to latch onto the nipple and successfully suckle but also about the logistical challenges. Where can women discretely breastfeed (ladies rooms are private, but not generally clean enough or adequately supplied with chairs, etc)? When can she feed the baby? Breast pumps are helpful collecting milk, but they do not seem to provide the same contraceptive protection baby suckling does. Ensuring that the woman has answers to each of these real-world issues may make lactational amenorrhea an adequate choice for a woman who intends to exclusively breastfeed her baby, but she needs to make plans about what method she would use should her menses return (loss of amenorrhea) or when she starts to supplement the baby's diet (with either formula or solid foods). This is particularly important to stress because exclusive breastfeeding rates drop dramatically within weeks of delivery. ${ }^{18}$

There may be a concern that women who are given other birth control methods may be less motivated to continue to breastfeed their infants. There is no evidence to support that hypothesis. Furthermore, putting a woman at increased risk for an early and unplanned pregnancy cannot be justified.

The most clinically important questions about breastfeeding and other forms of contraception revolve around the potential impacts that hormonal methods may have on the quality and quantity of breast milk available to the infant. Because postpartum milk letdown has been associated with the drop in circulating levels of progesterone, the concern was that prompt postpartum initiation of progestin methods would interrupt lactogenesis and lead to increased breastfeeding failure. Fortunately, a systematic review conclude that progestogen-only methods (implants, levonorgestrel intrauterine system [LNG-IUS], depot medroxyprogesterone acetate [DMPA], and progestin-only pills) do not adversely 
affect breastfeeding performance when used during lactation, and they did not adversely affect infant growth, health, or development. ${ }^{43}$ Even immediate initiation of progestin-only methods does not adversely impact lactogenesis or lactation discontinuation. ${ }^{44}$

Use of estrogen in the postpartum period is a category 4 condition in the US Medical Eligibility Criteria (MEC) because the postpartum period is the time of the highest risk for thrombosis. However, there has also been an additional concern that estrogen could adversely affect the quality and quantity of breast milk. Traditionally, estrogen-containing methods were not offered to breastfeeding women until the infant was at least 4 months old and solid foods were being introduced into his or her diet. The updated CDC US MEC guidelines now provide guidance about starting estrogen-containing methods during the postpartum period, ${ }^{4}$ and even newer data permit earlier use of combined hormonal contraceptives (CHCs) in breastfeeding women. ${ }^{45,46}$

Other issues have been raised about the use of hormonal methods in breastfeeding women. In one study, women with gestational diabetes who breastfed for more than 1 year and used progestin-only methods faced more than $85 \%$ increased risk of developing diabetes during that time. ${ }^{47}$ It is important to note that even in the face of this increased risk, more than $97 \%$ of such women did not develop diabetes. Other concerns about compounding lactation-related estrogen deficiency by use of progestin-only methods relates to their effect on the vaginal epithelium (HIV vulnerability, dyspareunia). In contrast, one recent investigation found that progestin-only pills prevented breastfeeding-related bone loss. ${ }^{7}$

\section{Postpartum contraception options Permanent contraception}

Because of legal requirements, women who request postpartum tubal ligation must have prenatal counseling. While this counseling involves the discussion of contraceptive options, recent studies have highlighted significant problems with both the existing antepartum consent process itself and the real-life availability of procedures postpartum. In one study, $46.7 \%$ of permanent contraception (sterilization) requests remained unfilled. ${ }^{48}$ Half of unfilled requests for permanent contraception have been attributed to Medicaid barriers. ${ }^{48}$ According to Medicaid requirements, informed consent must be obtained at least 30 days prior to the woman's estimated date of delivery. The reading level of those consents exceeds the abilities of many US women. ${ }^{49}$ Copies of the woman's signed consent must be available to the physician who is to do her procedure. A lack of coordination between clinics and hospitals can result in failure to deliver the needed paperwork to the hospital where the woman delivers. ${ }^{50}$ If existing requirements were to be amended so that the 30 day wait period was eliminated, it has been estimated that there would be 29,000 fewer unwanted pregnancies each year and \$215 million would be saved. ${ }^{50}$ Today, an increasing number of hospitals (generally those with specific religions affiliations) do not permit those procedures to be offered at all.

Concerns about selective delivery of postpartum tubal ligations were raised by another retrospective study in which only 45 of the 87 women who had wanted postpartum tubal ligation actually had their procedures as planned. Women who were older and those who had cesarean deliveries were more likely to get the surgery done, while married women and those with higher body mass indices were far less likely. ${ }^{50}$ The consequences of not performing the procedures when the women request it were highlighted in another study. Comparing the 133 women who requested, but did not get tubal ligation performed, to a matched control group with similarly poor attendance at their postpartum appointments $(20.3 \% \mathrm{vs}$ $18.8 \%$ ), the percentage of the women who got pregnant within 12 months was twice as high among those who did not get their desired procedures done (46.7\% vs $22.3 \%) .{ }^{51}$ It was as if the women who requested surgical treatments knew they would not be successful with other methods. The American College of Obstetricians and Gynecologists has recognized the importance of providing timely postpartum permanent contraception and quotes a $51 \%$ repeat pregnancy rate within 1 year of delivery if women do not have their procedures performed during that hospitalization. The committee opinion urges that the consent for permanent contraception be simplified and standardized, and recommends that postpartum sterilization be considered an urgent surgical procedure..$^{52}$

\section{Contraception implants}

One of the most appropriate methods to offer women in the immediate postpartum period is the contraceptive implant. This is particularly true for adolescents. ${ }^{53,54}$ The US MEC rates women who are less than 21 days postpartum as category 1 for implant use. The American Academy of Pediatrics urges that implants and IUDs be considered first-line contraceptive options for adolescents. For breastfeeding women in the early postpartum period, implants carry a level 2 rating. The reason that the implant is so very highly rated is that there is not any increase in serious adverse effects with immediate postpartum placement. There is no concern for venous thromboembolism risks. No significant adverse effects have been observed in women's weight, blood 
pressure, lipid profile, or hemoglobin if implants are given immediately postpartum. ${ }^{55}$ The expulsion rates with immediate postpartum placement are no higher than when they are placed later. Uterine involution may be slowed by progestin; one study found that lochia persisted $13 \pm 3$ days in implant users compared with $12 \pm 4$ days in nonusers. ${ }^{55}$ Therefore, women who have low hemoglobin levels may be better served by waiting to place the implant until lochial flow stops. In a group of 40 women randomized to the contraceptive implant, placed between 24 and 48 hours postpartum, versus DMPA initiated at 6 weeks, headaches were more commonly reported by implant users (45\% vs $10 \%)$. ${ }^{55}$ In contrast, $50 \%$ of women admitted having had intercourse before their 6 week visit, even though they had been instructed to practice abstinence for those weeks. ${ }^{55}$ Breastfeeding is not compromised by early (day 1-3) placement when compared with more traditional placement at $4-8$ weeks postpartum. Stage II lactogenesis occurred at $64.3 \pm 19$ hours vs the $65.2 \pm 18.5$ hours seen in the delayed-placement group. Use of formula did not differ between groups. At 6 weeks, milk composition was not different between the two groups. ${ }^{44}$ In another study, no significant adverse impacts were observed in infant weight gain or breastfeeding continuation..$^{55}$ Interestingly, one third of the women who were randomized to delayed implant placement never received their implants, reinforcing the need for placement during delivery hospitalization. ${ }^{44} \mathrm{In}$ addition to the safety of and convenience afforded by implant placement prior to discharge home, the placement procedure itself is not technically challenging, nor is it urgent to place the implant at the time of delivery. For women who have decided on implant use during prenatal counseling, there is plenty of time during hospitalization to ensure the woman gets her procedure performed. For women who have not had adequate prenatal counseling, there is still time after delivery for them to decide to initiate its use. This is in contrast to the urgency of placing an IUD within 10 minutes of delivery of the placenta.

Implants are particularly popular with adolescent women. In a study of 171 adolescents who participated in a prenatalpostnatal, prospective, observational study, implant continuation at 6 months was $96.9 \%$ (156/161 participants) with no pregnancies; at 12 months, the continuation rate remained high, at $85.6 \%$ (131/153), and only $2 \%$ had experienced pregnancy. In contrast, in the control group of 225 teenagers, $9.9 \%$ were pregnant by 6 months and $18.6 \%$ were pregnant by 12 months. ${ }^{56}$ Implants work well in women of all ages. In a retrospective study of 262 women who had immediate postpartum placement of contraceptive implants, the cumulative
3 year continuation rate was $66.3 \%$. Continuation rates were highest among women at highest risk for rapid repeat and unintended pregnancies. ${ }^{57}$

When women who received their implant within 96 hours of delivery were compared with women who had them placed in the more traditional 6-12 week postpartum period and with women who had "interval placement," there were no differences in the rates of request for early removal for any adverse effects; those rates were $19.3 \%, 18.4 \%$, and $20.8 \%$, respectively. Time to request for removal was almost indistinguishable among the groups; median length of implant use was 11, 13, and 10.5 months, respectively, for each group. ${ }^{58}$

\section{Postpartum IUDs}

The greatest enthusiasm in the recent obstetrician-gynecologist literature has been for the immediate placement of IUDs after delivery. ${ }^{1,2}$ A good deal of this enthusiasm comes from the strong evidence of benefits of immediate placement and of high continuation rates at 6 and 12 months. ${ }^{59-61}$ However, a good deal of the calls for immediate placement comes from realization that if women are not provided IUDs immediately, they are highly likely to never get them. In part, this may be due to local cutbacks in family planning funding ${ }^{56}$ but also to other access and use problems. Studies have documented that only $45 \%-60 \%$ of women who request IUDs return for postpartum placement. ${ }^{59,60,64}$ The US MEC rates placement of copper IUD within 10 minutes of placental delivery as a category 1 condition. Placement of a LNG-IUS at any time within the first 4 weeks of delivery is rated a category 2 condition, as is placement of a copper IUD between 10 minutes and 4 weeks. After 4 weeks, placement of any IUD is rated category 1 . The only category 4 condition is sepsis. These high ratings reflect the fact the advantages of immediate IUD placement far outweigh not only risks, but also potential disadvantages. ${ }^{63}$

The US MEC recognized that IUD expulsion rates are "somewhat higher" when an IUD is placed before 4 weeks but, also notes that 6 month continuation rates are similar between women who receive IUD postpartum and those who have delayed placement. ${ }^{59,62}$ Cumulative expulsion rates at 12 months were $12.3 \%$ for an immediate postplacental placement group ${ }^{62}$ compared with rates of $3.3 \%-9.2 \%$ for IUDs placed 6-8 weeks postpartum. ${ }^{60}$ In a systematic review, placement of the LNG-IUS at the time of cesarean delivery was associated with expulsion rates of 5-15 per 100 women-years compared with a rate of slightly above $5 \%$ if placed 6 or more weeks after surgery. ${ }^{64}$ Several earlier studies showed much 
lower expulsion rates at the time of cesarean section. ${ }^{65-67}$ A subsequent randomized controlled study of LNG-IUS placement during cesarean section versus placement 4-8 weeks later found higher expulsion rates in the immediateplacement group ( $20 \%$ vs $0.0 \%$ ), but confirmed that continued use at 12 months was not statistically different $(60.0 \%$ vs $40.9 \% ; P=0.35) .{ }^{61}$ It should be noted that placement of an IUD in breastfeeding women has been associated with more than a $1 \%$ uterine perforation rate, which is at least 6 times higher than in nonbreastfeeding women. ${ }^{64,68}$ On a positive note, breastfeeding women are far less likely to experience unscheduled bleeding or spotting following IUD placement postpartum, but it should be remembered that progestin-only methods may prolong postpartum lochia. ${ }^{64}$

IUD placement techniques are clearly different in the immediate postpartum period. At the time of cesarean section, several techniques have been described to place the IUD through the uterine incision and guide it up to the uterine fundus, but few investigators have described the techniques they have used to place tail strings through the cervix so that they will be accessible for easy removal. ${ }^{63,69}$ One concern about this lack of attention to the IUD threads is that many of the IUDs with "missing strings" will require more invasive procedures for IUD removal when the time comes. Following a vaginal delivery, IUDs have been placed with ring forceps or digitally, either by palpitation or under ultrasound guidance. Again, these techniques require extra training and experience and may not be in the comfort zone of primary care providers.

Recently, the labeling for the LNG-IUSs has been altered to clarify that those IUDs should not be placed before the woman is at least 6 weeks postpartum. If uterine involution is incomplete at that time, IUD placement should be delayed even longer to minimize the risk for uterine perforation. In the face of this documented risk, it is prudent to counsel women that all these early IUD placements are off-label.

\section{DMPA injections}

Because DMPA is safe in the postpartum period, with virtually no contraindications; because it offers at least shortterm, convenient pregnancy protection; and because it is significantly less expensive than the implants and IUDs, intramuscular DMPA has been frequently used as a bridge contraceptive through the postpartum period. Use of DMPA removes some of the urgency surrounding decision making and commitment to the longer-acting methods during this rather hectic period. For women who have not previously been counseled about the more effective methods, use of DMPA postpartum provides them a chance to focus on what they consider to be more urgent matters of their physical and social adjustments to motherhood and to address the needs of their newborn babies. There is no statistically significant evidence that early DMPA injections will interfere with lactogenesis or lactation success. ${ }^{69}$ In an observational study, women who selected progestin-only methods did not decrease or discontinue breastfeeding at any higher rates at 2, 4, or 6 weeks than did women who used nonhormonal methods, even though the women who used the progestin-only methods tended to be younger and less experienced with breastfeeding. ${ }^{18}$ Because breastfeeding women are already hypoestrogenic, DMPA does not markedly increase postpartum bone density loss. Given that the postpartum period is fraught with mood swings (resulting from thyroid fluctuations, sleep deprivation, body image changes, and new relationship stresses) and even more serious problems with postpartum depression, it is important to know that administration of DMPA in the immediate postpartum period does not appear to increase a woman's risk of developing postpartum depression. ${ }^{70}$ To measure the effect of DMPA on postpartum body weight and body fat changes, DMPA users were compared with women who had undergone permanent contraceptive surgeries postpartum. After 1 year, the DMPA recipients did not differ from the control group in either issue. Almost half the DMPA users returned to prepregnancy weight, and nearly half gained weight (generally, those latter women had high prepregnancy body mass indexes). ${ }^{71}$ However, the impact that progestin has slowing uterine involution is even important with DMPA because postpartum bleeding may be noticeably prolonged. One faith-based hospital started forbidding the use of DMPA for any indications and found, after adjusting for appropriate factors, that the earlier use of DMPA had significantly reduced repeat pregnancy (OR, $0.27 ; 95 \% \mathrm{CI}, 0.10-0.72) .{ }^{72}$ Adolescent mothers who chose DMPA, transdermal patches, or oral contraceptives had 1 year pregnancy rates of $14.2 \%$, $31.8 \%$, and $29.7 \%$, respectively. DMPA users were much more likely to be using any form of hormonal contraception at 12 months than $\mathrm{CHC}$ users. ${ }^{73}$ Although injections may be more effective than $\mathrm{CHC}$ methods, the failure rates with DMPA are higher than they are with IUDs or implants. ${ }^{74}$ Satisfaction rates were high at 6 months, and $80 \%$ of DMPA users planned to continue to use injections; however, by 12 months, only $42.9 \%$ still relied on injections. No such decrease in use was seen among LNG-IUS users. ${ }^{75}$

DMPA use as a contraceptive bridge has been used more frequently in public hospitals serving indigent, high-risk women than private hospitals. ${ }^{76}$ However, given the low rate 
of attendance indigent women have at postpartum visits in which women would be offered first tier methods, DMPA given postpartum can be a bridge to nowhere for many of these women. ${ }^{77}$

\section{Progestin-only pills}

For women who have not decided on a more effective method and those who do not like injections, progestinonly pills are available. The progestin-only pills are most commonly used for postpartum women, especially those who are breastfeeding. US MEC rates their use starting at any time after delivery as category 1 . Despite concerns that progestin-only pills require more consistent on-time ingestion than combined pills, analysis shows that in typical use, the first-year failure rates are the same as any of the estrogencontaining methods. ${ }^{74}$

Progestin-only pills are the go-to pill in just about every situation, because they have only one contraindication: recent breast cancer. However, it may be even more challenging for a new mother to remember to take a daily pill. Also, progestin-only pills may cause prolonging of postpartum bleeding. ${ }^{78}$

\section{Combined hormonal methods}

The postpartum period is the time of greatest risk for thrombosis. Recent investigations have revealed that the odds of developing a thrombosis remains elevated for 12 weeks postpartum. Compared with the risk of thrombosis at 1 year after pregnancy, the risk during the first 6 weeks is 10.8 times higher, and it is two times higher in weeks 7-12. ${ }^{79}$

The US MEC has recognized differences among different women in incidence of thrombosis postpartum, based on risk factors. Women without additional risk factors for venous thromboembolism (either personal or pregnancy-related risk factors) are category 2 for estrogen-containing methods as early as 21 days postpartum. Women who do have any of those risk factors are category 3 and should delay initiation of CHCs until 42 days (6 weeks) postpartum. Breastfeeding is a category 3 condition for the first month postpartum, but a recent study showed that combined hormonal methods started at 3-4 weeks did not adversely affect breastfeeding continuation rates or infant growth parameters compared with women given progestin-only methods. ${ }^{45}$

\section{Barrier methods}

Coitus is not recommended postpartum until all bleeding and spotting stops. If coitus occurs before closure of the cervix, a female condom may provide slightly better infection protection than other barriers. Spermicides may help not only with pregnancy prevention, but also lubrication. With a male condom, intercourse can inject vaginal pathogens into the endometrial cavity. With the hypoestrogenism that accompanies breastfeeding, dyspareunia may be exacerbated with male condom use. Use of other female barrier methods (cervical cap, diaphragm) generally must wait until about 6 weeks postpartum, when the cervix and vagina normalize.

\section{Behavioral methods}

Coitus interruptus can always be used as a method, in case the couple does not have any other method available. Data on postpartum efficacy of coitus interruptus is not available, but in general, first year failure rates in typical use for withdrawal are roughly equivalent to the failure rates of female barrier methods. Again, couples should not engage in sexual intercourse until postpartum infection vulnerability is minimized.

Classically, it has been said that women cannot rely on fertility awareness methods postpartum. However, hand-held fertility monitors, which test for urinary changes in estrogen and luteinizing hormones, have been found to be helpful during the transition between postpartum amenorrhea and resumption of menses. ${ }^{80}$

\section{Conclusion}

The paradigm for pregnancy care is rapidly changing the counseling and testing that was formally done at the first prenatal visit has now been shifted into preconception care. The content of the postpartum visit has also changed. Focus is on early adjustment to mothering, depression screening, and breastfeeding. The timing of that visit has been moved much closer to delivery. With clear evidence of the need to expand the use of implants and IUDs and the appropriateness of providing them as part of delivery service, efforts are being made to reduce financial barriers to that practice. This shifts the timing of counseling about postpartum contraception to the prenatal period. Women have requested that information about their postpartum contraception choices be explained to them in bite-size messages throughout their pregnancies, so they can have to make these decisions on an informed basis. With more widespread adoptions of these practices, it is hoped that interpregnancy intervals will be optimized and healthier pregnancies can be expected.

\section{Disclosure}

The author has received funding for research from Agile Therapeutics and Bayer and honoraria for speakers bureau 
and/or advisory board consultation from Actavis, Bayer, ContraMed, Merck, MicroCHIPS, Pfizer, PharmaNest, and Teva. The author reports no other conflicts of interest in this work.

\section{References}

1. Speroff L, Mishell DR Jr. The postpartum visit: it's time for a change in order to optimally initiate contraception. Contraception. 2008;78(2): 90-98.

2. Aiken AR, Creinin MD, Kaunitz AM, Nelson AL, Trussell J. Global fee prohibits postpartum provision of the most effective reversible contraceptives. Contraception. 2014;90(5):466-467.

3. Rodriguez MI, Evans M, Espey E. Advocating for immediate postpartum LARC: increasing access, improving outcomes, and decreasing cost. Contraception. 2014;90(5):468-471.

4. Centers for Disease Control and Prevention (CDC). Update to CDC's US Medical Eligibility Criteria for Contraceptive Use, 2010: revised recommendations for the use of contraceptive methods during the postpartum period. MMWR Morb Mortal Wkly Rep. 2011;60(26):878-883.

5. Centers for Disease Control and Prevention. US Selected Practice Recommendations for Contraceptive Use, 2013. Available from: http:// www.cdc.gov/reproductivehealth/unintendedpregnancy/usspr.htm. Accessed November 18, 2014.

6. American Academy of Pediatrics, American College of Obstetrics and Gynecologists. Guideline for Prenatal Care. 7th ed. Elk Grove Village, IL: American College of Obstetricians and Gynecologists; 2012.

7. ACOG Committee Opinion No ACOG Committee Opinion No 577: Understanding and using the US Selected Practice Recommendations for Contraceptive Use, 2013. Obstet Gynecol. 2013;122(5):1132-1133.

8. Caird LE, Reid-Thomas V, Hannan WJ, Gow S, Glasier AF. Oral progestogen-only contraception may protect against loss of bone mass in breast-feeding women. Clin Endocrinol (Oxf). 1994;41(6):739-745. Oxf.

9. Zhu BP. Effect of interpregnancy interval on birth outcomes: findings from three recent US studies. Int J Gynaecol Obstet. 2005;89(Suppl 1): S25-S33.

10. Zhu BP, Rolfs RT, Nangle BE, Horan JM. Effect of the interval between pregnancies on perinatal outcomes. N Engl J Med. 1999;340(8): 589-594.

11. Rodrigues T, Barros H. Short interpregnancy interval and risk of spontaneous preterm delivery. Eur J Obstet Gynecol Reprod Biol. 2008; 136(2):184-188

12. DeFranco EA, Stamilio DM, Boslaugh SE, Gross GA, Muglia LJ. A short interpregnancy interval is a risk factor for preterm birth and its recurrence. Am J Obstet Gynecol. 2007;197(3):264.e1-264.e6.

13. Centers for Disease Control and Prevention (CDC). Vital signs: Repeat births among teens - United States, 2007-2010. MMWR Morb Mortal Wkly Rep. 2013;62(13):249-255.

14. Nerlander LM, Callaghan WM, Smith RA, Barfield WD. Short Interpregnancy Interval Associated with Preterm Birth in US Adolescents. Matern Child Health J. Epub July 26, 2014.

15. Gemmill A, Lindberg LD. Short interpregnancy intervals in the United States. Obstet Gynecol. 2013;122(1):64-71.

16. Jackson E, Glasier A. Return of ovulation and menses in postpartum nonlactating women: a systematic review. Obstet Gynecol. 2011;117(3): 657-662.

17. Morán C, Alcázar LS, Carranza-Lira S, Merino G, Bailón R. Recovery of ovarian function after childbirth, lactation and sexual activity with relation to age of women. Contraception. 1994;50(5):401-407.

18. Halderman LD, Nelson AL. Impact of early postpartum administration of progestin-only hormonal contraceptives compared with nonhormonal contraceptives on short-term breast-feeding patterns. Am J Obstet Gynecol. 2002;186(6):1250-1256.

19. Baldwin MK, Edelman AB. The effect of long-acting reversible contraception on rapid repeat pregnancy in adolescents: a review. $J$ Adolesc Health. 2013;52(4)(Suppl):S47-S53.
20. Byrd JE, Hyde JS, DeLamater JD, Plant EA. Sexuality during pregnancy and the year postpartum. J Fam Pract. 1998;47(4):305-308.

21. Bloch JR, Webb DA, Mathew L, Culhane JF. Pregnancy intention and contraceptive use at six months postpartum among women with recent preterm delivery. J Obstet Gynecol Neonatal Nurs. 2012;41(3): 389-397.

22. Centers for Disease Control and Prevention (CDC). Contraceptive use among postpartum women - 12 states and New York City, 2004-2006. MMWR Morb Mortal Wkly Rep. 2009;58(30):821-826.

23. Potter JE, Hopkins K, Aiken AR, et al. Unmet demand for highly effective postpartum contraception in Texas. Contraception. 2014;90(5): 488-495.

24. Ogburn JA, Espey E, Stonehocker J. Barriers to intrauterine device insertion in postpartum women. Contraception. 2005;72(6):426-429.

25. Kogan MD, Leary M, Schaetzel TP. Factors associated with postpartum care among Massachusetts users of the Maternal and Infant Care Program. Fam Plann Perspect. 1990;22(3):128-130.

26. DiBari JN, Yu SM, Chao SM, Lu MC. Use of postpartum care: predictors and barriers. J Pregnancy. 2014;2014:530769.

27. Thiel de Bocanegra H, Chang R, Menz M, Howell M, Darney P. Postpartum contraception in publicly-funded programs and interpregnancy intervals. Obstet Gynecol. 2013;122(2 Pt 1):296-303.

28. Bergin A, Tristan S, Terplan M, Gilliam ML, Whitaker AK. A missed opportunity for care: two-visit IUD insertion protocols inhibit placement. Contraception. 2012;86(6):694-697.

29. Howell EA. Lack of patient preparation for the postpartum period and patients' satisfaction with their obstetric clinicians. Obstet Gynecol. 2010;115(2 Pt 1):284-289.

30. Depiñeres T, Blumenthal PD, Diener-West M. Postpartum contraception: the New Mexico Pregnancy Risk Assessment Monitoring System. Contraception. 2005;72(6):422-425.

31. Hernandez LE, Sappenfield WM, Goodman D, Pooler J. Is effective contraceptive use conceived prenatally in Florida? The association between prenatal contraceptive counseling and postpartum contraceptive use. Matern Child Health J. 2012;16(2):423-429.

32. Wilson EK, Fowler CI, Koo HP. Postpartum contraceptive use among adolescent mothers in seven states. $J$ Adolesc Health. 2013;52(3): $278-283$.

33. Krans EE, Davis MM, Schwarz EB. Psychosocial risk, prenatal counseling and maternal behavior: findings from PRAMS, 2004-2008. Am J Obstet Gynecol. 2013;208(2):141.e1-141.e7.

34. Zapata LB, Murtaza S, Whiteman MK, et al. Contraceptive counseling and postpartum contraceptive use. Am J Obstet Gynecol. Epub August 2, 2014.

35. Lopez LM, Hiller JE, Grimes DA, Chen M. Education for contraceptive use by women after childbirth. Cochrane Database Syst Rev. 2012;8:CD001863.

36. Cwiak C, Gellasch T, Zieman M. Peripartum contraceptive attitudes and practices. Contraception. 2004;70(5):383-386.

37. Day T, Raker CA, Boardman LA. Factors associated with the provision of antenatal contraceptive counseling. Contraception. 2008;78(4):294-299.

38. Yee L, Simon M. Urban minority women's perceptions of and preferences for postpartum contraceptive counseling. J Midwifery Womens Health. 2011;56(1):54-60.

39. Kofinas JD, Varrey A, Sapra KJ, Kanj RV, Chervenak FA, Asfaw T. Adjunctive social media for more effective contraceptive counseling: a randomized controlled trial. Obstet Gynecol. 2014;123(4):763-770.

40. Tang JH, Dominik RC, Zerden ML, Verbiest SB, Brody SC, Stuart GS. Effect of an educational script on postpartum contraceptive use: a randomized controlled trial. Contraception. 2014;90(2):162-167.

41. Torres L, Turok DK, Sanders J, Clark E, Godfrey E. Focused contraceptive counseling and case management versus usual care in women postpartum from a preterm birth: a random controlled trial. Contraception. 2014;90(3):317.

42. Gartner LM, Morton J, Lawrence RA, et al; American Academy of Pediatrics Section on Breastfeeding. Breastfeeding and the use of human milk. Pediatrics. 2005;115(2):496-506. 
43. Kapp N, Curtis K, Nanda K. Progestogen-only contraceptive use among breastfeeding women: a systematic review. Contraception. 2010;82(1): 17-37.

44. Gurtcheff SE, Turok DK, Stoddard G, Murphy PA, Gibson M, Jones KP. Lactogenesis after early postpartum use of the contraceptive implant: a randomized controlled trial. Obstet Gynecol. 2011;117(5): 1114-1121.

45. Espey E, Ogburn T, Leeman L, Singh R, Ostrom K, Schrader R. Effect of progestin compared with combined oral contraceptive pills on lactation: a randomized controlled trial. Obstet Gynecol. 2012;119(1):5-13.

46. Bahamondes L, Bahamondes MV, Modesto W, et al. Effect of hormonal contraceptives during breastfeeding on infant's milk ingestion and growth. Fertil Steril. 2013;100(2):445-450.

47. Kjos SL. After pregnancy complicated by diabetes: postpartum care and education. Obstet Gynecol Clin North Am. 2007;34(2):335-349, x.

48. Zite N, Wuellner S, Gilliam M. Barriers to obtaining a desired postpartum tubal sterilization. Contraception. 2006;73(4):404-407.

49. Zite NB, Philipson SJ, Wallace LS. Consent to Sterilization section of the Medicaid-Title XIX form: is it understandable? Contraception. 2007;75(4):256-260.

50. Boardman LA, DeSimone M,Allen RH. Barriers to completion of desired postpartum sterilization. $R$ I Med J (2013). 2013;96(2):32-34.

51. Thurman AR, Janecek T. One-year follow-up of women with unfulfilled postpartum sterilization requests. Obstet Gynecol. 2010;116(5): 1071-1077.

52. Committee on Health Care for Underserved Women. Committee opinion no 530: access to postpartum sterilization. Obstet Gynecol. 2012;120(1):212-215

53. Han L, Teal SB, Sheeder J, Tocce K. Preventing repeat pregnancy in adolescents: is immediate postpartum insertion of the contraceptive implant cost effective? Am J Obstet Gynecol. 2014;211(1): 24.e1-24.e7.

54. Tocce K, Sheeder J, Python J, Teal SB. Long acting reversible contraception in postpartum adolescents: early initiation of etonogestrel implant is superior to IUDs in the outpatient setting. $J$ Pediatr Adolesc Gynecol. 2012;25(1):59-63.

55. Brito MB, Ferriani RA, Quintana SM, Yazlle ME, Silva de Sá MF, Vieira CS. Safety of the etonogestrel-releasing implant during the immediate postpartum period: a pilot study. Contraception. 2009;80(6): 519-526.

56. Tocce KM, Sheeder JL, Teal SB. Rapid repeat pregnancy in adolescents: do immediate postpartum contraceptive implants make a difference? Am J Obstet Gynecol. 2012;206(6):481.e1-481.e7.

57. Wilson S, Tennant C, Sammel MD, Schreiber C. Immediate postpartum etonogestrel implant: a contraception option with long-term continuation. Contraception. 2014;90(3):259-264.

58. Ireland LD, Goyal V, Raker CA, Murray A, Allen RH. The effect of immediate postpartum compared to delayed postpartum and interval etonogestrel contraceptive implant insertion on removal rates for bleeding. Contraception. 2014;90(3):253-258.

59. Chen BA, Reeves MF, Hayes JL, Hohmann HL, Perriera LK, Creinin MD. Postplacental or delayed insertion of the levonorgestrel intrauterine device after vaginal delivery: a randomized controlled trial. Obstet Gynecol. 2010;116(5):1079-1087.

60. Celen S, Möröy P, Sucak A, Aktulay A, Danişman N. Clinical outcomes of early postplacental insertion of intrauterine contraceptive devices. Contraception. 2004;69(4):279-282.

61. Whitaker AK, Endres LK, Mistretta SQ, Gilliam ML. Postplacental insertion of the levonorgestrel intrauterine device after cesarean delivery vs delayed insertion: a randomized controlled trial. Contraception. 2014;89(6):534-539.
62. Kapp N, Curtis KM. Intrauterine device insertion during the postpartum period: a systematic review. Contraception. 2009;80(4):327-336.

63. Grimes DA, Lopez LM, Schulz KF, Van Vliet HA, Stanwood NL. Immediate post-partum insertion of intrauterine devices. Cochrane Database Syst Rev. 2010;(5):CD003036.

64. Goldstuck ND, Steyn PS. Intrauterine contraception after cesarean section and during lactation: a systematic review. Int J Womens Health. 2013;(5):811-818.

65. Levi E, Cantillo E, Ades V, Banks E, Murthy A. Immediate postplacental IUD insertion at cesarean delivery: a prospective cohort study. Contraception. 2012;86(2):102-105.

66. Chi IC, Ji G, Siemens AJ, Waszak CS. IUD insertion at cesarean sectionthe Chinese experience. Adv Contracept. 1986;2(2):145-153.

67. Nelson AL, Chen S, Eden R. Intraoperative placement of the Copper T-380 intrauterine devices in women undergoing elective cesarean delivery: a pilot study. Contraception. 2009;80(1):81-83.

68. van Grootheest K, Sachs B, Harrison-Woolrych M, Caduff-Janosa P, van Puijenbroek E. Uterine perforation with the levonorgestrelreleasing intrauterine device: analysis of reports from four national pharmacovigilance centres. Drug Saf. 2011;34(1):83-88.

69. Brownell EA, Fernandez ID, Fisher SG, et al. The effect of immediate postpartum depot medroxyprogesterone on early breastfeeding cessation. Contraception. 2013;87(6):836-843.

70. Tsai R, Schaffir J. Effect of depot medroxyprogesterone acetate on postpartum depression. Contraception. 2010;82(2):174-177.

71. Nyirati CM, Habash DL, Shaffer LE. Weight and body fat changes in postpartum depot-medroxyprogesterone acetate users. Contraception. 2013;88(1):169-176.

72. Guiahi M, McNulty M, Garbe G, Edwards S, Kenton K. Changing depot medroxyprogesterone acetate access at a faith-based institution. Contraception. 2011;84(3):280-284.

73. Thurman AR, Hammond N, Brown HE, Roddy ME. Preventing repeat teen pregnancy: postpartum depot medroxyprogesterone acetate, oral contraceptive pills, or the patch? J Pediatr Adolesc Gynecol. 2007;20(2): 61-65.

74. Hatcher RA, Trussell JA, Nelson AL, Cates W, Kowal D, Policar MS. Contraceptive Technology. 20th ed. New York: Ardent Media; 2011.

75. Howard DL, Wayman R, Strickland JL. Satisfaction with and intention to continue Depo-Provera versus the Mirena IUD among post-partum adolescents through 12 months of follow-up. J Pediatr Adolesc Gynecol. 2013;26(6):358-365.

76. Dozier AM, Nelson A, Brownell EA, Howard CR, Lawrence RA. Patterns of postpartum depot medroxyprogesterone administration among lowincome mothers. J Womens Health (Larchmt). 2014;23(3):224-230.

77. Berger A, Hinz E, Lackritz K, Woodhams E. Does a contraceptive bridge method affect rates of postpartum IUD placement in a resident urban clinic? Contraception. 2014;90(3):325.

78. Potter L, Oakley D, de Leon-Wong E, Cañamar R. Measuring compliance among oral contraceptive users. Fam Plann Perspect. 1996;28(4): $154-158$.

79. Kamel H, Navi BB, Sriram N, Hovsepian DA, Devereux RB, Elkind MS. Risk of a thrombotic event after the 6-week postpartum period. $N$ Engl J Med. 2014;370(14):1307-1315.

80. Bouchard T, Fehring RJ, Schneider M. Efficacy of a new postpartum transition protocol for avoiding pregnancy. J Am Board Fam Med. 2013;26(1):35-44. 
Open Access Journal of Contraception

Dovepress

\section{Publish your work in this journal}

Open Access Journal of Contraception is an international, peerreviewed, open access, online journal, publishing original research, reports, reviews and commentaries on all areas of contraception. In addition to clinical research, demographics and health-related aspects, the journal welcomes new findings in animal and preclinical studies

relating to understanding the biological mechanisms and practical development of new contraceptive agents. The manuscript management system is completely online and includes a very quick and fair peer-review system. Visit http://www.dovepress.com/testimonials.php to read real quotes from published authors.

Submit your manuscript here: http://www.dovepress.com/open-access-journal-of-contraception-journal 